\title{
Semelhanças e dissonâncias em espaços de ensinar e aprender
}

\author{
Similarities and dissonances in places of teaching and learning
}

Eliane Regina Pereira[ ${ }^{[a]}$, Neiva de Assis ${ }^{[b]}$, Andrea Vieira Zanella ${ }^{[c]}$, Kátia Maheirie ${ }^{[d]}$

\footnotetext{
${ }^{[a]}$ Doutora em Psicologia, professora da Universidade Federal de Uberlândia (UFU), Uberlândia, MG - Brasil, e-mail: eliane@ipsi.ufu.br

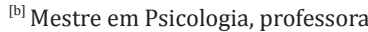
do Instituto Federal Catarinense, São Francisco do Sul, SC - Brasil, e-mail: neivapsi@hotmail.com

${ }^{[c]}$ Doutora em Educação (Psicologia da Educação), professora da Universidade Federal de Santa Catarina (UFSC), Florianópolis, SC - Brasil, e-mail: avzanella@ gmail.com

${ }^{[\mathrm{d}]}$ Doutorado em Psicologia (Psicologia Social), professora da Universidade Federal de Santa Catarina (UFSC), Florianópolis, SC - Brasil, e-mail: maheirie@chf. ufsc.br
}

Recebido: 02/03/2012 Received: 03/02/2012

Aprovado: 04/10/2012 Approved: 10/04/2012

\section{Resumo}

Este texto se propõe a fazer dialogar duas pesquisas que investigaram ações complementares ao ensino regular, de modo a dar visibilidade às semelhanças e às dissonâncias entre ONG e circo-escola. Ambas as pesquisas investigaram os sentidos produzidos por jovens sobre as atividades desenvolvidas para além dos muros escolares, dentro de serviços de ações complementares à escola. Tendo como referência as contribuições de Vygotsky e autores do círculo de Bakhtin, enfocamos neste texto a dimensão dos sujeitos que participam das ações complementares, as experiências tal como vivenciadas nessas atividades e os sentidos que jovens produzem sobre elas. Por meio de entrevistas com os jovens aprendizes e observações no cotidiano dessas ações, destacamos as relações nesses espaços mediadas pela afetividade e pelo aumento da potência de ser. Movimento afetivo-volitivo que permitiu aos aprendizes e jovens irem além de si mesmos, além do que estava posto, instituído. A relação entre educadores e jovens aprendizes mediou o aprender e necessariamente constituiu e constitui sujeitos que se fazem permanentemente aprendizes. Consideramos, à guisa de conclusão, ONG e circo-escola como espaços de potência para a criação e a recriação das relações de ensinar e aprender, fundamentalmente em virtude do modo como as linguagens artísticas são ali trabalhadas.

Palavras-chaves: Ações complementares à escola. Relações de ensinar-aprender. Potência de ação.

\section{Abstract}

This text proposes to discuss two studies that investigated after-school activities complementary to regular education, in order to give visibility to the similarities and divergences among NGO's and school-circus. Both studies investigated the meanings produced by young people about the activities beyond the school walls, within the services that complement the school's activities. Having as reference the contributions of Vygotsky and Bakhtin, we focus in this paper on the dimension of the subjects participating in after-school activities, their experiences in these activities and the meanings that young people give to them. Through interviews with young learners and observations in the daily life of these actions, we highlight that the relationships existent in these places were mediated by increased warmth and power of action. An affective-volitional movement which allowed apprentices and young people to go beyond themselves, beyond what

Psicol. Argum. 2014 jul./set., 32(78), 39-49 
was said and has been instituted. The relationship between teachers and young learners has mediated the learning process and necessarily has constituted the subjects which are permanently learners. We consider, in conclusion, that NGO's and school-circus are places of power for creation and recreation, and for the relationship of teaching and learning, fundamentally because of the way they worked with artistic languages.

Keywords: After-school activities. Teaching-learning relationships. Power of action.

\section{Introducão}

Em nossas trajetórias profissionais deparamos com inúmeras e significativas histórias de produção do fracasso escolar, o que se tornou para nós um incômodo e contribuiu para definir, como projeto profissional, a busca pela reinvenção das relações de ensinar e aprender.

Atuamos em políticas públicas de atenção à infância e à juventude em municípios no interior de Santa Catarina, que oportunizaram o contato com ações complementares à escola. Definimos como ações complementares à escola as mais diversas atividades denominadas: "Contraturno Escolar"; "Programa Jornada Ampliada"; "Educação Complementar"; "Educação em Tempo Integral"; "Escola em Tempo Integral" ou, ainda, "Segundo Tempo", conforme a política pública a que se vincula e o público alvo atendido (Assis, 2011).

Essas ações indicam o aumento progressivo do tempo de permanência de jovens na escola ou em espaços educativos em consonância com a Lei de Diretrizes e Bases da Educação Nacional - LDBEN 9.394 (Brasil, 1996). 0 Artigo 34, Parágrafo Segundo, determina que:

\begin{abstract}
A jornada escolar no ensino fundamental incluirá pelo menos quatro horas de trabalho efetivo em sala de aula, sendo progressivamente ampliado o período de permanência na escola. [...] 0 ensino fundamental será ministrado progressivamente em tempo integral, a critério dos sistemas de ensino.
\end{abstract}

Para atender a essa diretriz, observa-se um significativo número de programas e serviços implementados de ações complementares à escola, seja por meio de políticas públicas governamentais, não governamentais ou privadas, que tem se constituído como alternativa para manter os jovens ocupados para além das quatro horas diárias em sala de aula.
Compreendemos que essas ações, além de propiciar um espaço de ocupação ou proteção das crianças e dos adolescentes, podem ampliar seu repertório cultural potencializando "conhecimentos, fazeres, valores e habilidades exigidos na vida cotidiana e explorar com eles oportunidades lúdicas, artísticas e esportivas" (Cenpec, 2003, p. 14).

Diferentes são os espaços e as propostas de ações complementares: oficinas organizadas nas escolas estaduais e municipais de tempo integral; atividades artísticas vinculadas às Secretarias da Assistência Social ou ONGs com ações dirigidas às populações que vivem em situação de vulnerabilidade social, entre outros. Mas todos têm como semelhança a perspectiva do aumento do tempo de jovens em instituições educativas.

Mas é importante questionar que ações são essas? 0 que há nelas que mantém os jovens vinculados? É possível que essa ampliação permita novas relações com o processo de ensinar e aprender? Podem contribuir para a reinvenção dos modos de fazer a própria escola regular?

Diante desses questionamentos, desenvolvemos duas investigações em cidades de médio porte de Santa Catarina. A primeira intitulada "Jovens, Arte e Cidade: (Im)possibilidades de relações estéticas em Programas de Contraturno Escolar" (Assis, 2011), investigando os sentidos das atividades artísticas para jovens participantes de um programa de contraturno escolar; o lugar social dessas atividades; os discursos produzidos pelos jovens sobre si no contato com esse espaço institucional; bem como a busca de relações estéticas estabelecidas com as atividades artísticas oferecidas.

A segunda, intitulada "Aprendendo a ser circense e ampliando as possibilidades de 'ser' aprendiz" (Pereira, 2011), teve como foco investigar de que forma a arte circense, compreendida como atividade criadora e experiência estética, mediadas pela afetividade, aumenta a potência de ação do sujeito e amplia as possibilidades de "ser aprendiz". 
Ambas as pesquisas ${ }^{1}$ investigaram ações complementares ao ensino regular, e neste artigo propomos fazê-las dialogar de modo a dar visibilidade às semelhanças e às dissonâncias entre $\mathrm{ONG}$, circo-escola e escola, e a investigar os sentidos produzidos por jovens sobre as atividades desenvolvidas para além dos muros escolares, dentro de serviços de ações complementares à escola. Tivemos como referência as contribuições de Vygotsky e Bakhtin, enfocamos a dimensão dos sujeitos que participam de atividades artísticas nas ações complementares, as experiências tal como vivenciadas nessas atividades e os sentidos que jovens produzem sobre elas.

\section{Algumas aproximações teóricas}

Para a realização das investigações e do diálogo entre elas, partimos da perspectiva histórico-cultural que compreende a constituição do sujeito como processo sempre inacabado, em que seu "Eu" é inconcluso e resulta do modo como interage socialmente e se apropria do contexto em que vive. Compreendemos, a partir de Vygotsky (2000), que o sujeito se constitui ao se apropriar dos sentidos produzidos nas relações com os outros. É no coletivo e a partir dele que o sujeito se singulariza, marcando a condição necessariamente social de todos e de cada um. Mas essa apropriação se dá de forma singular, ou seja, cada sujeito se apropria das coisas e das relações do mundo de forma única, a partir do momento e do lugar que ocupa, em um específico conjunto de circunstâncias.

Somos únicos porque cada relação que vivenciamos é irrepetível, mas ao mesmo tempo somos semelhantes porque vivemos em um mesmo contexto histórico e, por esse motivo, não fugimos aos limites da época e das suas condições de possibilidade.

Portanto, o sujeito se constitui na relação com um outro, em uma relação de alteridade. A alteridade é conceito fundamental na teoria bakhtiniana e, apesar de fazer pouco uso do termo, sua

1 Todos os procedimentos cumpriram os requisitos do Comitê de Ética em Pesquisa com seres humanos da Universidade Federal de Santa Catarina, por meio do Termo de Consentimento Livre e Esclarecido - TCLE. Todos os nomes apresentados neste artigo são fictícios. compreensão também é fundamental em Vygotsky. Zanella (2005, p. 103) destaca que “(...) só há sujeito porque constituído em contextos sociais, os quais, por sua vez, resultam da ação concreta de seres humanos que coletivamente organizam seu próprio viver".

Portanto, o sujeito não é apenas produto das forças externas, mas produz e é produzido em seu contexto. 0 processo de constituição do sujeito se dá em um espaço de conflito, produção permanente, diferenças, semelhanças e tensões. Ou seja, em um mundo de significações produzidas nos encontros com muitos outros e particularmente apropriadas (Zanella, 2005).

As discussões e as investigações sobre alteridade tratam de mostrar o outro como diferença, desvendando suas características e especificidades. Reafirmamos, assim, o inacabamento do sujeito; ao se relacionar com um "outro" que lhe confere acabamento, define-se como alguém. Se consideramos que são inúmeros os outros com os quais o sujeito estabelece relações de alteridade, podemos dizer que esse sujeito torna-se espaço de síntese de múltiplos olhares sobre si.

Contextos educativos consistem em lugares de constituição dos sujeitos, de relações com os outros, de mediação com a cultura, de singularização da coletividade, de (re)produção de sentidos e cultura. ONG, circo-escola ou escola regular se fazem espaços privilegiados de síntese subjetiva e, portanto, é fundamental pensar sobre o modo como esses lugares educativos contribuem para a constituição dos sujeitos que deles participam.

Ao retomar alguns elementos históricos e sociais para a compreensão da institucionalização da educação e as diferentes configurações educacionais no contexto contemporâneo, destacamos Ariés (1981) que afirma que, entre os séculos XIV e XIX, a escola tornou-se instituição indispensável para iniciar a vida social e a aprendizagem, isolando a juventude do mundo adulto e controlando-a. Segundo o autor, durante esse período, os jovens entre 12 e 20 anos passavam mais tempo em instituições educativas e retardavam a entrada no mundo do trabalho.

No século XX, com o processo de urbanização e industrialização, os jovens foram confinados no interior das famílias e nas escolas, distanciando-os de seus grupos de pertença e das situações vivenciadas no entorno de onde vivem. A instituição educação passa a ocupar um lugar administrativo, jurídico e

Psicol. Argum. 2014 jul./set., 32(78), 39-49 
institucional de controle da juventude. ${ }^{2}$ Dispositivo que estabelece a disciplina, vigilância e enquadramento da juventude. E, portanto, é instituição conservadora de um modo pretendido de viver em sociedade e reprodutora cultural e social de determinados grupos e classes (Peralva, 1997).

Historicamente, a escola não tem favorecido espaços de aprender, prevalecendo a ordem e a manutenção das regras em detrimento das possibilidades de invenção de novas práticas sociais. No Brasil, desde a década de 1970, várias pesquisas têm demonstrado a educação como prática utilitária, a serviço de uma cultura hegemônica. Lembramos as pesquisas sobre a produção do fracasso escolar e a medicalização do ensino, realizadas por Patto (1993), Moysés e Collares (1996), entre outros.

Mas as ações complementares ao ensino regular podem se caracterizar de modo diferente? Podem vir a ser espaço potencializador de processos criativos aos jovens? Ou se reduziriam a ser novos espaços de submissão e exercício da autoridade destinados à juventude contemporânea?

Podemos dizer que existem experiências educativas potencializadoras da juventude, como as discutidas e propostas pelo Cenpec - Centro de Estudos e Pesquisas em Educação, Cultura e Ação Comunitária (2006). ${ }^{3}$ Essa organização defende uma educação que tenha a vida cotidiana como base, espaço no qual se objetivam as ações humanas e não apenas uma aposta no aumento de tempo de escola para melhorar o desempenho escolar. Essa organização traz a ideia de espaços de educação complementar como proteção social para jovens em situação de pobreza, como complemento sócio-educativo às atividades oferecidas na escola.

As ações de educação complementar desenvolvidas dos mais diversos modos possuem sua

2 Assim como em Áries (1981), Coimbra (2001), Castro \& Correa (2005), Caccia-Bava et al. (2004), Peralva (1997) e Sposito (2004), compreende-se juventude com uma visão aberta, incluindo as particularidades que não se enquadram em uma visão totalizadora.

${ }^{3}$ O Cenpec segmento da sociedade civil desde 1987 reúne profissionais com laços na academia (tais como Bader Sawaia e Isa Guará) e na gestão pública da educação. Trabalham com as demandas da política pública de educação no país. Ver mais em: www.cenpec.org.br. relevância na medida em que facilitam o acesso e a fruição de outras oportunidades culturais (Gonçalves, 2006).

Contudo, instigadas a conhecer as relações que os jovens estabelecem com a escola, a ONG e a escola-circo, procuramos analisar e compreender algumas cenas mais de perto e destacar possibilidades educacionais que viabilizem a reinvenção dos modos de estar com os outros e de se fazer escola.

\section{As investigações: seus textos e contextos}

As duas investigações que serviram de dispositivo para a discussão sobre possibilidades educativas em contextos de ações complementares à escola possuíam objetivos e procedimentos específicos distintos entre si. Mas ambas trouxeram como perspectiva a possibilidade de ampliação do tempo de escolarização e a intencionalidade na oferta de atividades diversificadas e alternativas ao ensino regular.

A escolha desses fragmentos revela os afetos que experienciamos na condição de pesquisadoras, no encontro com a beleza das narrativas dos sujeitos entrevistados. Nossas palavras trazem as escolhas que realizamos para a construção que apresentamos.

\section{A primeira investigação: o "Circo-escola"}

O circo-escola é vinculado a um instituto que o mantém, e se propõe a ensinar a arte circense a crianças e adolescentes moradores de um município catarinense. Essa organização oferece oportunidade de atividade no contraturno escolar para aproximadamente 120 jovens.

As atividades acontecem sob uma lona de circo, o que determina a primeira diferença da escola regular. 0 circo-escola conta com quatro educadores, artistas circenses, que organizam atividades circenses em duas turmas, com aulas diárias de 1 hora e 30 minutos. Ensinam trampolim, malabares, paradas de mão, corda bamba, trapézio, entre outras atividades. A aula é iniciada com aquecimento e, depois, 40 minutos de atividade física intensa com exercícios aeróbicos. Após esse período, os aprendizes são separados em pequenos grupos e iniciam atividades direcionadas às modalidades circenses de seu interesse. 
A investigação realizada nesse contexto iniciou com observação das aulas e de algumas apresentações realizadas nas cidades próximas. Após esse período foram entrevistados quatro educadores e doze aprendizes circenses. Nas entrevistas com os educadores, objetivávamos compreender as relações de ensinar e aprender do ponto de vista do educador: como percebiam seu aprendiz, como compreendiam o aprender, como e o que avaliam no processo de ensinar e aprender. Além disso, procuramos conhecer a história de vida dos educadores-artistas, a fim de identificar aspectos da formação que se fazem presentes no seu ensinar.

Nas entrevistas com os doze aprendizes, procuramos investigar de que forma o circo-escola surgiu na vida deles; como definiam essa atividade, os sentimentos envolvidos na relação com o público; com os educadores e amigos; como significavam esse espaço de aprender; qual sua relação com a escola regular; como percebiam sua aprendizagem.

Destacamos, para análise nesse texto semelhanças e dissonâncias entre a escola regular e o circo-escola, um fragmento das entrevistas com os aprendizes da escola de circo em que questionamos qual a relação estabelecida entre os dois espaços educativos. Obtivemos respostas que afirmavam não haver qualquer relação entre esses espaços: "não, uma coisa é uma coisa, e outra coisa é outra coisa (...). Aqui você faz uma coisa que você gosta e lá não gosta, faz por obrigação" (Samantha).

Outra entrevistada, Berenice traz mais informações sobre essas diferenças:

acho que não, as coisas são bem diferentes aqui e na escola. Lá cada matéria tem conteúdo diferente, aqui não, cada aparelho tem um tipo de exercício, mas é tudo junto. Tudo que tu aprende na escola tem cada coisa separada, não pode misturar tudo junto, matemática com geografia... E tem a concentração né, na hora de fazer prova concentradinha (...) é a única relação que eu vejo.

A fala de Berenice merece destaque, pois quando fala da não integração das matérias na escola regular, do quanto o ensinar encontra-se fragmentado em instâncias sem qualquer relação entre si, seguramente ela afirma que essa prática não possui relação com o circo-escola. A partir de sua fala, inferimos que na escola regular os conteúdos são engavetados, separados, fragmentados, enquanto no circo há a possibilidade de construir um aprender incorporado ao sujeito. Na escola regular o aluno raramente sabe porque aprende aquele conteúdo ou ainda, quais são os objetivos dessa aprendizagem, enquanto no circo-escola o saber e o fazer são indissociáveis.

Para os entrevistados, enquanto na escola regular o aluno sente-se obrigado a aprender, a obedecer, a ficar quieto, na escola de circo o aluno tem desejo de aprender, de conviver, de se concentrar.

O circo é um espetáculo fantástico (...) daí a gente está ali todo mundo e na hora da apresentação todo mundo ajuda todo mundo. Lá na escola não, é separado, tipo ou é em dupla ou é individual, essas coisas assim. 0 pessoal não se comunica muito, prova é todo mundo ali, sozinho, aqui na apresentação, todo mundo reunido é bem diferente. Lá a gente briga muito, lá tipo assim, o professor não que ele é exigente, aqui também é, só que tem uns professores que eles são estúpidos. Eles são grossos, não querem saber de nada, o problema é teu. Aqui não, aqui quer aprender, vem que eu te ensino, vamos lá, vamos conseguir. (Elena)

Elena destaca em sua fala a competitividade presente na escola regular, fala da individualização das relações, fala do distanciamento entre professores e alunos. E ao mesmo tempo fala das relações mais próximas que acontecem no circo, da preocupação do professor com a qualidade dessa relação que Elena sintetiza no "eu te ensino, vamos lá, vamos conseguir".

Elena nos deixou intrigadas, uma vez que durante as observações, identificamos nos educadores do circo-escola uma ação frequente de reclamar e mover simultaneamente a cabeça em sinal negativo, como se os exercícios estivessem sempre errados. 0 aprendiz executava a ação e eles gesticulavam, falavam alto e reclamavam muito, tudo ao mesmo tempo.

Por esse motivo, questionamos os aprendizes, sobre como se sentiam em relação a essa postura, como compreendiam essas críticas, tentando entender como os mobilizava. As falas revelam a motivação nascida nas críticas dos educadores: "eu me sinto assim ó, eu vou fazer de novo... Vou fazer de novo até eu conseguir... Vou fazer de novo, não quero nem saber se não está certo, vou fazer de novo" (Elena).

Psicol. Argum. 2014 jul./set., 32(78), 39-49 
É sobre ser afetada que Elena fala, pois quando diz "vou fazer de novo", ela se apropria da afetividade que se torna mediadora de uma reflexão, possibilitando que transcenda as condições existentes, em função de uma força individual, uma "potência de ação". Potência é, segundo Espinosa (1983) o aumento ou diminuição da capacidade de agir no encontro com outros sujeitos, com outros corpos. Em função desses encontros, o sujeito pode se apropriar mais ou menos do seu corpo, aumentando ou diminuindo suas possibilidades.

Desse modo, a escola de circo é vista como espaço que possibilita "bons encontros", pois promove o diálogo e a vivência com a alteridade, diferentemente da escola regular que valoriza as relações individualizadas. Espinosa (1983) chama de "bons encontros" aqueles que potencializam o sujeito, encontros nos quais o sentir, o pensar e o agir - como forma de objetivação do sujeito - encontram-se em congruência e são potencializados.

É com base em Espinosa e Vygotsky que Sawaia (2003) explica que a vontade e a afetividade são dimensões fundamentais para a concretude da ação humana. Segundo a autora, os afetos aumentam ou deprimem a capacidade de agir dos sujeitos e esclarece que negar ou menosprezar o afeto na ação educativa é inibir a potência de ação.

Como os afetos são gerados nos encontros com o outro, o caminho da recuperação da afetividade não está na força interior e no autoesforço, e sim na coletividade, nas relações face à face que singularizam as relações sociais dominantes, definindo como cada um é afetado nos encontros com o outro (Sawaia, 2003, p. 59).

A afetividade é, então, mediadora dos acontecimentos objetivos, portanto, é para aquele educador e para si mesma que Elena decide fazer de novo. 0 mesmo acontece com Berenice e Ana:

eles são exigentes do ponto deles. São exigentes pra ajudar a gente, pra você fazer melhor... é só pra te incentivar, porque se ele falar que você está bem, você não vai mais querer fazer, entendeu? Pra eles é assim, o esforço que eles fazem é pra gente mesmo, entendeu? Eles ajudam mais a gente, do que eles mesmos. É para o nosso bem. Eles são bem atenciosos em tudo (Berenice).

Ah! eu tento fazer o meu melhor. Se eles tão me criticando é porque tem uma coisa errada, eles não vão me criticar por criticar, eu vou fazer o meu melhor. Se eu errar, beleza, eu vou chegar e vou falar, ó Smirnov e Ludmila, eu não consegui, isso não é pra mim, eu espero que outra pessoa tente e consiga. A gente só conversa assim, é conversando que se entende (Ana).

Os educadores estabelecem uma relação de desafio e ao mesmo tempo de respeito aos limites, às escolhas, às possibilidades e às impossibilidades do aprendiz. A afetividade determina o sentido da crítica do educador, que é significada por Berenice e Ana como sendo mobilizadora do aprender mais, aprender melhor. 0 mesmo significado pode ser identificado nas falas de Samantha e Hugo sobre o educador:

ele sabe fazer a gente se enraivar... ele quer que a gente prove pra ele, prove pra pessoa dele, que a gente tem capacidade. Depois que a gente faz isso, parece uma maravilha, né, não incomoda mais a gente (Samantha).

Todas as críticas são para aprender... você precisa organizar o corpo, se ficar mole, todo molenga, pode cair de cabeça e morrer ali... se tá todo mole, todo curvado, primeiro aprende a botar o corpo no lugar, depois vai aprender a pular, que é o principal... e assim vai indo (Hugo).

0 que Samantha e Hugo revelam é a importância do afeto dirigido pelo educador, da aposta, do desafio, do ensino qualificado, enquanto potencializadores de uma nova racionalidade, de uma nova forma de pensar, sentir e agir. Falam de um educador que observa o outro como sujeito de desejos e possibilidades e que explora esse aspecto ao utilizar o desejo como fonte para aprender. Falam de um educador cuja postura ético-afetiva, (re)significa o modo como cada um dos seus aprendizes se faz sujeito no mundo, "se enraivando" e mostrando capacidade ou ainda organizando o corpo para aprender.

Duarte Jr. (2010, p. 26) destaca que "é preciso possibilitar ao educando a descoberta de cores, formas, sabores, texturas, odores, etc. diversos daqueles que a vida moderna lhe proporciona". Podemos inferir que isso acontece no circo-escola, pois se os educadores tiveram suas sensibilidades desenvolvidas e cuidadas, como artistas que são, possivelmente, conseguem ofertar o mesmo aos seus 
aprendizes, e isso parece ter sido descrito nas falas até aqui destacadas.

0 que os educadores de circo parecem fazer é conhecer o momento atual do desenvolvimento físico e emocional dos aprendizes, e com esse saber conseguem criar novas necessidades, novos desejos para suas vidas e fazem mediação na constituição dos aprendizes.

Assim, como o poeta pinta com palavras para que a poesia seja vista e não entendida, os educadores do circo-escola ensinam com o corpo, para que o aprender seja sentido, experienciado, marcado e potencializador das possibilidades desses corpos.

Outro aspecto discutido com os aprendizes foi se percebiam alguma melhora significativa no aprender relacionado à escola regular, após o ingresso na escola de circo. E a fala de Samantha sintetiza o que ouvimos também dos outros: "olha, melhorar posso até ter melhorado, porque a gente pensa assim, ah vou melhorar pra não tirar nota baixa e ser afastado do circo" (Samantha).

Resposta recheada de desejo pela escola de circo, relação que se faz afetivo-volitiva. 0 único efeito direto de uma escola sobre a outra é fundado no receio da perda do espaço, do lugar no circo, do sujeito que está sendo constituído na escola de circo. Um sujeito que aprende porque gosta, porque deseja, conhecendo suas dificuldades e independente das obrigações.

É possível afirmar que o circo-escola, como possibilidade de educação complementar, (des)absolutiza o aprender. 0 aprender é visto como processo, como construção e vivido psicofisicamente pelo sujeito, que compreende seu corpo, possibilidades e limites e explora-os, ultrapassa a si mesmo. Aprende a ser artista, aprende a ser sujeito, que tem garra, que sabe que é capaz, que supera diariamente seus problemas.

\section{A segunda investigação - a ONG}

A ONG, na perspectiva da educação complementar, oferece atividades em contraturno escolar para jovens com idades entre 6 e 16 anos, nos turnos matutino e vespertino. Ao iniciar suas atividades em 2006, atendia 25 crianças no turno vespertino e mantinha-se com recursos da comunidade local, empresas parceiras e voluntários que desenvolviam atividades educativas. A partir de 2007, a ONG vinculou-se à Secretaria Municipal de Assistência Social, dentro da política de proteção social básica, no Sistema Único de Assistência Social - SUAS, e passou a receber recursos para execução de atividades de Jornada Ampliada para famílias que se encontram com os direitos violados e/ou em famílias em situação de vulnerabilidade social. ${ }^{4}$

As atividades incluem alimentação, apoio escolar e ações educativas no contraturno escolar para 50 jovens. 0 prédio utilizado pela organização educativa assemelha-se a uma residência aconchegante, de cor azul, janelas brancas e grandes, com varandas no piso térreo e no andar superior. As varandas são coloridas e apresentam ilustrações e desenhos com motivos infantis e alegres nas paredes; decorações produzidas pelos próprios participantes. Chama a atenção a presença do jardim bem cuidado, com folhagens, grama e árvores e a ausência de muros em oposição ao cimento tão presente em contextos de escolarização formal. Condição física que aparece como intencionalidade no documento da proposta educativa: um espaço para ações diversificadas e alternativas àquelas oferecidas no ensino regular. A instituição realiza atividades como apoio pedagógico, apoio as tarefas escolares; oferta de alimentação: almoço e lanche; e oficinas artísticas, como música e mosaico.

A investigação nesse contexto iniciou com um período de observação e participação no interior da organização educativa e seguiu por meio de distintos procedimentos de produção de informações, repensados e reinventados no próprio processo de pesquisar: encontros conjuntos com dois grupos de jovens e conversa com três educadores. Nesse processo foi necessário incluir como procedimento conversas acompanhando quatro jovens no trajeto entre a ONG/ escola como alternativa para encontrá-los em um contexto que permitisse a emergência de sentidos e maior liberdade de expressão, considerando a vigilância institucional e os modos cristalizados e hierarquizados que encontrei na organização educativa.

\footnotetext{
${ }^{4}$ A Política Nacional de Assistência Social define como público alvo: cidadãos e grupos que se encontram em situações de vulnerabilidade e riscos tais como: famílias e indivíduos com perda ou fragilidade de vínculos afetivos, exclusão pela pobreza e, ou, no acesso às demais políticas públicas, estratégias e alternativas de sobrevivência que podem representar risco pessoal e social (Brasil, 2004).
}

Psicol. Argum. 2014 jul./set., 32(78), 39-49 
Em um primeiro momento, com uso de uma máquina fotográfica manual caseira disponibilizada a cada participante para que registrassem o trajeto, as coisas e os lugares que chamavam a atenção, enfim, o que desejassem registrar durante o trajeto pela cidade. E, em um segundo momento, outra conversa individual com os jovens no espaço da instituição educativa para buscar os sentidos sobre as atividades que participam cotidianamente na ONG.

Trazemos para análise nesse texto uma cena registrada em diário de campo durante o período de observação do cotidiano dessa ONG, a qual apresenta discursos de diferenças e semelhanças entre escola e ONG. Nessa cena, algumas crianças de nove e oito anos no refeitório cumprimentaram: "oi, Professora", subentendendo que a pesquisadora fosse uma professora. Diante disso alguns questionamentos surgiram. Haveria necessidade de definir hierarquicamente lugares sociais no espaço escolar?

No contexto da escolarização, a hierarquização "[...] supõe explicação, ficção distributiva, justificadora de uma desigualdade que não tem outra explicação, senão sua própria existência" (Ranciére, 2007, p. 162). Impôs-se a necessidade de problematizar o lugar comum, o discurso conhecido, a ideia partilhada de ser professor que emergiu por ali (Smolka, 2006).

No diálogo estabelecido esclarecemos que éramos visitantes e não professoras. Uma das meninas respondeu que gostavam de visitas, só não das visitas das pessoas da escola. Isso porque em algumas situações, coordenadores, orientadores e professores do ensino regular visitam a ONG para conhecer o espaço ou conversar sobre o desenvolvimento escolar de crianças que frequentam escola e ONG paralelamente. E a menina continuou: "Porque só vem aqui falar mal da gente". E outras duas meninas reafirmaram: "verdade, só vem aqui falar da gente". Posteriormente em conversa com a coordenadora, foi possível compreender que a ONG promove reuniões, cafés com as diretoras, orientadoras e professores das escolas das crianças. E que nesses encontros, professores da escola saem incomodados ao ver que as crianças realizam as atividades e participam ativamente das propostas da ONG, em oposição aos seus comportamentos na escola regular.

Haveria outras cores na ONG não presentes na escola? Poderia a escola aprender a pintar o ensino regular com tonalidades (des)conhecidas? Essas meninas do refeitório estudavam em uma escola que oferecia aos interessados atividades em tempo integral; o que significa dizer que o currículo escolar era organizado de modo a incluir as disciplinas obrigatórias do ensino regular e outras atividades complementares pertinentes à ampliação da jornada escolar. Havia, portanto, programação durante todo o dia na escola próxima da casa daquelas meninas, mas elas preferiam frequentar o contraturno escolar na ONG, assim como seus irmãos e tantos outros do percurso dessa pesquisa. Relataram que preferiam frequentar a ONG e fizeram críticas às pessoas da escola e aos modos de fazer a escola.

Nessa investigação foi ficando evidente que, aos olhos dos jovens, ONG e escola carregam sentidos diversos, são lócus de possibilidades e impossibilidades. Destacaram a dificuldade em aprender os conteúdos da escola e, em contrapartida, as muitas coisas que aprendem na ONG. "A escola é burra e aqui não", conta uma menina e tensiona o lugar do aluno que não aprende, desloca a ideia de culpabilização do aluno para o processo de ensinar e aprender ao considerar que "burros" não são os alunos, mas sim a escola que não atinge os objetivos para os quais foi criada.

Os jovens revelam ainda outros detalhes que demarcam o território escolar: "na escola tem sinal, aqui não tem" e "na escola todo muito sai junto (tem tumulto), na ONG não". Contavam que na ONG fazem passeios legais como ir ao Parque do Beto Carrero, cachoeira, piscina. E continuaram: "a comida do curso é uma delícia. Na escola, só às vezes, não tem suco", contou Estela. Marcaram as regras rígidas, o lugar do não, da impotência no contexto escolar e destacaram os afetos e o acesso à diversão presentes na ONG.

Meninos e meninas preferem ir à ONG e não ao ensino regular. Dizia Michele: "aqui é tudo legal" indicando que a ONG, com todas as suas contradições e particularidades, alarga e revitaliza a esfera da educação pública (Carvalho, 2006).

Todos os jovens pesquisados optam por frequentar a ONG, ao invés da escola regular, mas, ao mesmo tempo, destacam o "não ter nada pra fazer" em casa no contraturno da escola como justificativa principal para participar das atividades ali desenvolvidas. Justificativa que de certo modo denuncia a ausência de políticas públicas de cultura, esporte, profissionalização aos jovens pesquisados, próximas aos locais em que residem.

O que os motiva? "Ah, as professoras tratam a gente bem. A professora é legal com a gente", contou Kauê. Para além das atividades serem ou não 
atrativas do ponto de vista de alguns dos jovens, outros aspectos os atraem para a ONG. A ONG se constituiu como lugar de bons encontros, de afetos, lugar de calor (Sawaia, 1995), lugar de construção de laços de amizades que extrapolam o espaço físico. Amizades construídas na própria ONG, presentes na memória afetiva dos jovens pesquisados. $\mathrm{Na}$ companhia dos novos amigos encontrados na ONG frequentam "teen party" juntos, tornam-se amigos, "ficantes" de moradores de outros bairros e, assim, aproximam localidades distantes geograficamente.

Michele, por exemplo, destacou um evento organizado pela ONG no ano de 2009 para as famílias, os voluntários e os colaboradores da entidade em que três meninos apresentavam uma música que aprenderam durante o ano, na oficina de violão. Michele contou sobre um dos meninos: "O André, agora não vem mais [...] Ele cantava também. Ele também tocava violão com a gente. Um dia que a gente foi lá na $\mathrm{AABB}^{5}$ eu cantei e eles tocaram violão".

André, a quem Michele se refere não participa mais das atividades na ONG, nem encontra mais seus amigos de lá. Apesar disso, ele foi destacado e lembrado pelos amigos no diálogo em que os afetos se fizeram presentes.

Destacamos a experiência dos jovens em compartilhar com seus pares a atividade artística e os sentidos produzidos na apresentação dessas habilidades artísticas em um evento na ONG. 0 diálogo foi tornando possível o enraizamento da experiência, constituindo lugares de memória como "aquilo que não só passa, mas fica; que persiste; que perdura que reitera; que significa" (Smolka, 2006, p. 106).

Mas se as relações afetivas são destacadas como aspecto positivo na ONG, aos olhos dos jovens são justamente as atividades de cunho mais diretamente pedagógico e com finalidades cognitivas que não gostam naquele contexto. Durante os encontros conjuntos, lembraram de algumas atividades de que participam ali e explicaram que são distribuídas no decorrer dos dias da semana: informática, dança, violão, mosaico, apoio pedagógico. E complementaram:

É chato ficar copiando do quadro. [...] Me esqueci o nome daquele negócio.. De ensino, pedagógico [...] É o apoio pedagógico. Tira isso e coloca outro no

5 Associação Atlética do Banco do Brasil. lugar. [...] Tipo a professora passa uma pergunta, a gente tem que fazer no caderno pra mostrar pra ela. Daí ela corrige, vê se tá certo, daí se não tiver... Ela passa no quadro e a gente copia (Michele).

Ou seja, o apoio pedagógico na ONG tem as mesmas características das atividades desenvolvidas na escola regular tradicional.

Por outro lado, ao buscar potências na ONG, as oficinas de musicalização, mosaico e, de modo geral, aquelas que incluíam diferentes linguagens artísticas se configuraram como experiência impactante, com significação aos olhos dos jovens. Ao conversar com Michele sobre a produção de sons com copos na oficina de musicalização ela comenta: "Na primeira vez eu já peguei. [...] Agora a gente tá aprendendo outros ritmos". E complementou contando com gestos como produziram os sons com o copo: "a gente vira [o copo]. É bate assim. [na mesa] Daí vira [o copo]. Quando bate, pega o copo de volta".

E assim foi contando da satisfação e da habilidade em desenvolver os ritmos com os copos, reconhecendo a complexidade da atividade de musicalização na ONG. Contava que chegavam a cansar, que por vezes a professora interrompia, chamando a atenção para que cantassem direito, orientando sobre o ritmo do copo, do violão. "Às vezes ela mandava tipo, alguém que não tava cansada. [...] Daí um pouco de cada vez descansava."

Observamos que, de certo modo, a inclusão das oficinas artísticas possibilitou outras relações dos jovens consigo mesmos. A inclusão da arte, no processo de ensinar e aprender no contraturno escolar desacomodou o lugar do aluno problema, daquele que não aprende. Conhecemos jovens que carregavam as marcas de quem não se sai bem no processo de aprender na escola formal e que, na ONG, puderam experienciar atividades de potência, de capacidade, de sucesso. Com essas experiências puderam ressignificar as relações de ensinar e não aprender vividas na escola, o que certamente não passará sem deixar vestígios em suas trajetórias.

Assim ocorreu com um menino de 10 anos, que apesar de contar com alguns anos de escolarização, ainda não estava alfabetizado e carregava o rótulo de aluno problema. As experiências em meio à arte permitiram que fossem visualizadas suas potencialidades e não suas faltas: a noção de ritmo, de coordenação e o fato de ser o único a tocar pandeiro. Ser o único a tocar pandeiro, em meio a tantos jovens

Psicol. Argum. 2014 jul./set., 32(78), 39-49 
lhe conferiu outro lugar social, ${ }^{6}$ lugar simbólico que implica necessariamente a consideração de um outro. Lugar de quem é capaz de aprender atividades difíceis e complexas.

\section{Movimentos sobre os espaços educativos}

O que há de fato nas ações complementares à escola que mantém os aprendizes vinculados a elas? Podem esses espaços ser facilitadores de outras relações de ensinar e aprender em espaços de educação regular?

Os aprendizes do circo-escola e os jovens da ONG indicam o compromisso dos educadores desses espaços com o seu fazer e com um projeto de vir-a-ser para os aprendizes. E assim, sustentados nesse compromisso assumiram uma postura ético-afetiva com os aprendizes, priorizando um aprender que alcançava a experiência do sujeito e, assim, o modificava enquanto tal.

Ensinar e aprender, nesses dois contextos, tem como base a história dos educadores e, também, o cotidiano dos jovens e aprendizes, suas (im)possibilidades corporais e seu devir. Os aprendizes do circo-escola descreveram, em suas falas, educadores "rígidos e extrovertidos, bravos e alegres", mas, acima de tudo, amigos. Do mesmo modo, o espaço da ONG é significado pelos jovens como lugar de bons encontros, de afetos, de amizades, lugar de ser "bem tratado".

As relações nesses espaços foram, portanto, mediadas pela afetividade e pelo aumento da potência de ser. Foi esse movimento afetivo-volitivo que permitiu aos aprendizes e aos jovens irem além de si mesmos, além do que estava posto, instituído. A relação entre educadores e aprendizes mediou $o$ aprender e, necessariamente, constituiu e constitui sujeitos que se fazem permanentemente aprendizes.

Ao destacar as relações de ensinar e aprender vislumbramos um aprender que favoreceu uma condição corporal, mas, principalmente, se constituiu como espaço no qual novas possibilidades foram lançadas. Nesse contexto, pessoas (re)inventaram

${ }^{6}$ Zanella (2011) destaca o conceito de lugar social em substituição ao conceito de papel, apontando a inadequação desse último por não considerar a dialogicidade ou pluralidade de vozes características dos processos comunicativos. possibilidades para si e para os outros e, dessa forma, se projetaram para o futuro.

No circo-escola, o aprender foi entendido como sinônimo de experiência, como aquilo que tocou, marcou, transformou e constituiu os sujeitos. 0 "ser" afetado se apresentou no corpo, um corpo que se apropriou de forma sensível do mundo e a ele ofertou novos significados, um corpo que precisa, ainda, ser valorizado em outras relações de ensinar e aprender.

Embora tente se ocupar, assim como a escola regular, da disciplinarização da infância e da juventude, a ONG permitiu espaços possíveis para outros encontros e inovações. Ao buscar suas potências, deparamo-nos com as oficinas de musicalização, atividade que se configurou como experiência impactante, com significação aos olhos dos jovens. Experimentaram a produção de ritmos musicais com copos de cozinha, sintonizados com violão e diversas vozes e experimentaram serem outros para além dos espaços institucionalizados. Experiências como ser o único a tocar pandeiro, fazer sons com os copos de cozinha, conferiram à ONG lugar de potência aos olhos dos jovens.

Consideramos, portanto, ONG e circo-escola como espaços para a criação e recriação das relações de ensinar e de aprender. Contextos educativos complementares e alternativos ao trivializado no ensino regular, espaços potencializadores à medida que incluíam diversas linguagens artísticas nas atividades desenvolvidas.

Apontamos, portanto, para a possibilidade de extensão qualitativa do tempo educativo. Instituições educativas podem contribuir para a construção de um espaço coletivo, de potência com a juventude, o que por sua vez não é tarefa simples: importante se faz considerar, na composição dos programas de ações complementares ao ensino regular, os interesses dos jovens e priorizar uma educação que considere os sujeitos na sua potência criadora.

Esse tempo e espaço educativo ampliado devem permitir novas formas de aprender, ativada pelo aumento da potência de agir, onde a afetividade, a estética e a imaginação estejam em congruência, mobilizando os sujeitos em ações que possibilitem a constituição de lugares sociais outros, marcados pelo reconhecimento das possibilidades de cada um e de todos ensinarem e aprenderem. 


\section{Referências}

Ariés, P. (1981). História Social da Criança e da Família. 2 ed. Rio de Janeiro: LTC.

Assis, N. (2011). Jovens, Arte e Cidade: (Im)possibilidades de relações estéticas em Programas de Contraturno Escolar. Dissertação de Mestrado, Curso de PósGraduação em Psicologia, Universidade Federal de Santa Catarina, Florianópolis.

Brasil, Ministério da Educação e Cultura. (1996). Lei de Diretrizes e Bases da Educação Nacional. Brasília.

Brasil, Ministério de Desenvolvimento Social. (2004). Política Nacional de Assistência Social. Brasília.

Caccia-Bava, A; Pámpols, C \& Cangas, Y. G. (2004). Jovens na América Latina. São Paulo: Escrituras Editora.

Carvalho, M. C. B. C. (2006). O lugar da educação integral na política social. In: Cenpec - Centro de Estudos e Pesquisas em Educação, Cultura e Ação Comunitária. Educação Integral. Cadernos CENPEC. № 2.

Castro, L. R. \& Correia, J. (2005). Juventude Contemporânea: Perspectivas nacionais e internacionais. Rio de Janeiro: NAU Editora: FAPERJ.

Cenpec - Centro de Estudos e Pesquisas em Educação, Cultura e Ação Comunitária. (2003). Muitos Lugares para Aprender. São Paulo: Author.

Coimbra, C. (2001). Operação Rio - o mito as classes perigosas. Um estudo sobre a violência urbana, a mídia impressa e os discursos de segurança pública. Rio de Janeiro: Oficina do Autor; Niterói: Intertexto.

Duarte Jr., J. F. (2010). O sentido dos sentidos: a educação (do) sensível. Curitiba, Pr: Criar Edições.

Espinosa, B. (1983). Ética. (Marilena Chauí, Trad., Coleção Os Pensadores). São Paulo: Abril Cultural.

Gonçalves, A. S. (2006). Reflexões sobre educação integral e escola de tempo integral. IN: Cadernos Cenpec - Educação, Cultura e Ação Comunitária. n.o 2 Educação Integral.

Moysés, M. A. \& Collares, C. A. L. (1996). Preconceitos no Cotidiano escolar - ensino e medicalização. São Paulo: Cortez.
Patto, M. H. S. (1993). A produção do fracasso escolar: histórias de submissão e rebeldia, S.P, T.A.Queiroz, reimpressão.

Peralva, A. (1997). 0 jovem como modelo cultural. Revista Brasileira de Educação. Mai/Jun/Jul/Ago 1997 N 5 Set/Out/Nov/Dez no 6 .

Pereira, E. R. (2011). Aprendendo a ser circense e ampliando as possibilidades de "ser" aprendiz. Tese de Doutorado, Curso de Pós-Graduação em Psicologia, Universidade Federal de Santa Catarina, Florianópolis.

Sawaia, B. (1995). O Calor do Lugar - segregação urbana e identidade. São Paulo em. Perspectiva, São Paulo, Fundação Seade, v.9, n.2, p.20-24

Sawaia, B. (2003). Fome de felicidade e liberdade. In Cenpec (Centro de Estudos e Pesquisa em Cultura e Ação Comunitária). Muitos Lugares para aprender. (pp. 53-63). São Paulo, SP: UNICEF.

Smolka, A. L. B. (2006). Experiência e discurso como lugares de memória. In S. Z. Da Ros., K. Maheirie \& A. V. Zanella. Relações estéticas, atividade criadora e imaginação: sujeitos e (em) experiência. (pp. 117-30). Florianópolis: NUP/CED/UFSC.

Sposito, M. P. (2004). Alguns desafios para a compreensão das relações entre escola e juventude. In: JUBRA - Anais do Simpósio Internacional Sobre Juventude Brasileira.

Tittoni, J. (2009). Psicologia e Fotografia: Experiências em intervenções fotografias. Porto Alegre: Ed. Dom Quixote.

Vygotsky, L. S. (2000). Manuscrito de 1929. Educação e Sociedade, 21(71). Recuperado em dezembro de 2010, em http://www.scielo.br

Zanella, A. V. (2005). Sujeito e Alteridade: reflexões a partir da Psicologia Histórico-Cultural. Psicologia e Sociedade, 17(2). Recuperado em fevereiro de 2011, em http:// www.scielo.br

Zanella, A. V. (2011). Perguntar, registrar, escrever: inquietações metodológicas. Material submetido à publicação.

Psicol. Argum. 2014 jul./set., 32(78), 39-49 